\title{
O novo socialismo utópico e a importância da revolução política para o socialismo marxista
}

Sandra Regina Zarpelon ${ }^{1}$

A presente comunicação tem por objetivo discutir novos programas autodenominados socialistas ou comunistas que prescindem tanto da necessidade de tomada do poder político pelo proletariado, como da noção marxista de transição para a sua realização. Para argumentar contra tal noção de transformação radical da sociedade, usaremos as considerações de Etienne Balibar² e Luciano Martorano ${ }^{3}$ acerca da transição.

À corrente teórico-política que considera possível uma passagem tranqüila para o socialismo, daremos a denominação de "novo socialismo utópico", mesmo correndo o risco de cometermos algumas imprecisões. A própria análise desta corrente remete à constatação que os termos socialismo e comunismo são reivindicados por diversas correntes políticas e teóricas, sendo o marxismo uma delas. Assim, a esquerda não marxista tem se esforçado para dar respostas à ascensão do neoliberalismo e à crise que a esquerda de maneira geral tem vivido desde o fim das experiências denominadas soviéticas. Ao marxismo se coloca o desafio elaborar um programa socialista que

1 Mestranda do programa de pós-graduação do Departamento de Ciências Políticas da UNICAMP e pesquisadora do Cemarx.

2 Etienen Balibar, “Sobre os Conceitos Fundamentais do Materialismo Histórico". In: Louis Althusser et al. Ler o Capital. v. II, Rio de Janeiro, Editora Zahar, 1979.

3 Luciano Cavini Martorano, A Burocracia e os Desafios da Transição Socialista. São Paulo, Editoras Xamã e Anita Garibaldi, 2002.

94 novo socialismo utópico e a importância da revolução política para o socialismo marxista 
contemple, de um lado, a crítica ao modelo soviético e, de outro, uma resposta à ascensão da direita liberal. Não é nossa intenção aqui levantarmos as reflexões sobre um novo programa marxista; nos atemos a apresentar uma crítica de alguns programas socialistas não marxistas, enfatizando a contemporaneidade das análises marxistas de transição, luta de classes e revolução política.

Os programas discutidos nessa comunicação serão os de Alain Bihr ${ }^{4}$ e de Paul Singer ${ }^{5}$. De modo geral, estes programas têm em comum a defesa de um socialismo direto, construído nos interstícios da sociedade capitalista, e sem a postulação de uma ruptura política. Podemos dizer que o que os aproxima do socialismo utópico do século XIX, e que justifica, assim, a denominação de neoutópicos é a desconsideração ou a pouca importância dada aos antagonismos de classes presentes no capitalismo. Nos dois casos em análise, a revolução política é substituída: para Bihr, pela revolução microeletrônica; ou seja, é a revolução tecnológica, baseada na microeletrônica, que traz consigo o potencial da transformação social. Já Paul Singer substitui a revolução política pela revolução social socialista - lenta, não linear e contínua -, baseada na expansão da democracia e do cooperativismo.

O programa de Bihr se baseia num retorno ao sindicalismo revolucionário - portanto ao anarco-sindicalismo -, porém sem mencionar a necessidade da greve geral insurrecional. Esse autor considera que o aumento da produtividade advindo da revolução tecnológica pode ser usado pelo movimento operário para atender aos seus interesses históricos. Dessa forma, o programa de Bihr reserva para o sindicalismo um papel fundamental; tanto que todo o movimento operário é, na verdade, reduzido à dimensão de um sindicalismo com características revolucionárias.

A idéia geral de Bihr é que a partir de alguns objetivos ou reivindicações ralizáveis" do ponto de vista do atual estágio de desenvolvimento do capitalismo, o movimento operário chegaria a outros, estratégicos para a construção do comunismo. Assim, alguns objetivos a serem perseguidos pelo movimento operário podem servir de "escada" para se alcançar os objetivos estratégicos que levam ao comunismo.Tais objetivos são, basicamente: a redução em massa, rápida e geral da jornada de trabalho, a instituição de uma renda social garantida e a reorientação da produção, levando em

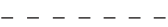

4 Alain Bihr, Da Grande Noite à Alternativa. São Paulo, Editora Boitempo, 1998.

5 Paul Singer, A Utopia Militante. Rio de Janeiro, Editora Vozes, 1999 e Paul Singer\& João Machado, Economia Socialista. São Paulo, Editora Fundação Perseu Abramo, 2000.

cadernos cemarx, $n^{0}-2-2005 \mid \mathbf{9 5}$ 
conta critérios ecológicos, de economia do trabalho necessário, da utilidade social e da cooperação internacional.

A partir dos dois primeiros objetivos, o movimento operário romperia com o produtivismo, com a divisão social do trabalho, com o culto ao trabalho e com o caráter mercantil da força de trabalho. Isto porque a diminuição drástica e geral da jornada, aliada à garantia de uma renda social universal levaria, segundo o autor, a uma reorientação do tempo de trabalho ao longo da vida do indivíduo, possibilitando longos períodos sabáticos, que poderiam ser usados para o aprendizado ou o aperfeiçoamento do trabalhador em outras áreas que não aquela a que está ligado no processo produtivo, diluindo, assim, a divisão rígida do trabalho. Além disso, uma renda garantida para tais períodos tiraria do salário sua caracterização forte, mostrando-se mais como a parte da produção social a que todos têm direito.Através do último objetivo - a reorientação produtiva - o movimento operário imporia limites ao desenvolvimento das forças produtivas, empurrando-as para um sistema democrático e integrado no plano mundial.

Para atingir tais objetivos, o movimento operário - reduzido praticamente ao sindicalismo - deve se aproveitar dos projetos de reestruturação produtiva e impor planos alternativos - ou contraplanos - que visem a redução da jornada de trabalho e a reorientação produtiva. A esses três objetivos - a redução em massa, rápida e geral da jornada de trabalho, a instituição de uma renda social garantida e a reorientação da produção - associa-se um quarto objetivo: a construção de uma "sociabilidade alternativa", que visaria a passagem de uma democracia política e formal, presente no capitalismo, para uma democracia social, que deve existir na vigência de uma sociedade comunista. As condições para se chegar a essa sociabilidade alternativa são indicadas pelo autor:

"fazer o maior campo possível de relações sociais e de práticas sociais escapar da influência do capital e, mais precisamente, de suas duas mediações principais, que são o mercado (as relações mercantis e monetárias) e o Estado (as relações burocratizadas do aparelho de Estado);

Prefigurar e preparar as condições institucionais mas também psicológicas da sociedade comunista, concebida como 'livre associação de indivíduos livres` (Marx), ampliando o campo tanto da soberania individual (o campo aberto ao projeto existencial de cada um) quanto a soberania coletiva, da auto-organização cooperativa das tarefas coletivas" ${ }^{6}$.

$-\cdots-\cdots$

6 Bihr, op. cit., p.202.

96 O novo socialismo utópico e a importância da revolução política para o socialismo marxista 
O autor coloca a revolução política como um mito a ser rompido através de sua estratégia. Para tanto, esta se baseia em três elementos gerais: o aproveitamento das "brechas" que o sistema capitalista oferece, o desenvolvimento de "contrapoderes" através de "contraprojetos" ou projetos alternativos, e a destruição do Estado, através da substituição gradativa da democracia representativa pela democracia direta.

Paul Singer procura sustentar a possibilidade de um socialismo construído nos interstícios do capitalismo utilizando como argumento central a tese de que os modos de produção não se tornariam hegemônicos através ou a partir de revoluções políticas, mas de revoluções sociais. Ele parte da análise sobre a consolidação do modo de produção capitalista para elaborar o seu programa socialista. Segundo a sua análise da transição do feudalismo para o capitalismo, este já vinha se desenvolvendo muito antes das chamadas Revoluções Burguesas. Na sua concepção, então, a transição do modo de produção feudal para o modo de produção capitalista se deu sob o domínio da economia sobre a política; ou seja, a partir do desenvolvimento das forças produtivas de tipo capitalista dentro do modo de produção feudal. O crescimento contínuo da produção capitalista gerou não só o desenvolvimento vertiginoso das forças produtivas, como também as "mudanças institucionais indispensáveis ao avanço das relações de produção capitalistas nos diversos países" ${ }^{7}$.

A revolução social socialista, por sua vez, teve seu início a partir da implantação de instituições que Singer considera anticapitalistas, através das lutas operárias. Estas instituições anticapitalistas seriam a legislação trabalhista, os sindicatos, as cooperativas de produção e de crédito e todas os elementos da democracia burguesa. Seu programa está baseado nas interações entre essas instituições anticapitalistas, principalmente entre os sindicatos e as cooperativas. Elas são ainda consideradas pelo autor como "implantes socialistas" dentro do capitalismo. Os implantes mais complexos são as cooperativas. Desta maneira, o programa socialista de Singer prevê basicamente o desenvolvimento e difusão das experiências cooperativistas como forma de, por um lado, promover o aprendizado das classes trabalhadoras sobre o funcionamento da produção e, de outro, disputar a hegemonia com o modo de produção capitalista. Na verdade, para ele, o cooperativismo é a essência do modo de produção socialista, já que altera as relações no interior da fábrica, as relações de propriedade e a própria divisão social do trabalho.

$-{ }_{--1--}$

7 Singer, op. cit., p.27.

cadernos cemarx, $n^{0} 2-2005 \quad 97$ 
Singer considera necessário recuperar a idéia de socialismo como sociedade mais justa e mais livre. O seu socialismo é essencialmente autogestionário, direto e construído a partir da base; e um programa socialista atual deve contemplar a luta pelo desenvolvimento dos "implantes socialistas" - principalmente das cooperativas -, e a pela expansão da democracia.

Singer pondera que os mercados devem permanecer como "planejadores" da economia. E para compensar as desigualdades promovidas pela permanência dos mercados, deveria haver a criação de uma renda cidadã, muito parecida com a renda social garantida nos termos de Bihr.

Tendo exposto, sintéticamente, os elementos mínimos para a compreensão de socialismo destes dois autores, faremos, a partir de agora, um esforço de reflexão sobre as propostas contidas nos seus programas, e sobre a noção de socialismo nelas embutida.

Singer e Bihr partilham da idéia de que é possível organizar a sociedade de forma socialista, sem que a classe operária detenha o poder de Estado ${ }^{8}$. Ou seja, para ambos, a forma como se organiza a estrutura jurídico-política não tem importância para a construção de uma sociedade socialista. Na verdade, mais do que programas, eles apresentam plataformas reivindicativas que, no limite, promoveriam alguma melhora nas condições de vida dos trabalhadores - isto é, uma espécie de humanização do capitalismo -, mas não o socialismo entendido como a "transformação - até a sua dissolução - das relações de produção capitalistas, com base no desenvolvimento das forças produtivas, e a desestatização socialista promovidas pelos trabalhadores ".

Concordamos com a concepção de Martorano, baseada nas considerações de Balibar, segundo a qual a transição para o socialismo só pode começar com a tomada do poder de Estado pela classe operária através da revolução proletária, afastando as classes dominantes e promovendo a construção de um novo Estado - socialista -, "defasado por 'antecipação' às relações de produção vigentes, ainda capitalistas"10 .

As considerações acima citadas têm como base o esboço de teoria da transição desenvolvido por Balibar em Sobre os Conceitos Fundamentais do Materialismo Histórico. Balibar, a partir da análise da transição do feudalismo para o capitalismo conclui que sem a implantação de um Estado capitalista não teria sido possível a constituição

$--{ }_{--1}^{-}-$

8 V. Prefácio de Armando Boito ao livro de Martorano já citado, p.13.

9 Martorano, op. cit., p.218.

10 Idem, p. 219.

98 O novo socialismo utópico e a importância da revolução política para o socialismo marxista 
do mercado de trabalho, elemento fundamental para o desenvolvimento do modo de produção capitalista. Assim, a transformação do político antecedeu a transformação econômica. Isto nos permite o equívoco contido na análise de Singer sobre a transição do feudalismo para o capitalismo, em especial, a sua ponderação de que o "desenvolvimento vertiginoso" das forças produtivas e o crescimento da produção de tipo capitalista teria levado às mudanças institucionais. Boito Jr. dá um tratamento diferente à questão, concluindo que o Estado absolutista não era de tipo capitalista, pois "reproduzia a estrutura econômica feudal e bloqueava um desenvolvimento de tipo capitalista. Dessa perspectiva, a revolução burguesa, entendida como um processo de transformação da estrutura do Estado e da correspondente mudança da classe social que detém o poder de Estado, adquire importância decisiva na transição ao capitalismo" ${ }^{11}$.

Apenas para concluir, reforçamos a idéia inicial sobre a necessidade de o marxismo refletir sobre um programa socialista, entendendo que os pontos de partida para tal empreitada são a definição do que é o socialismo e a elaboração de uma teoria da transição, capaz de dar conta dos problemas que a classe operária enfrentará num momento de crise revolucionária e a partir da sua vitória. Portanto, a esquerda marxista não deve se iludir com fórmulas fáceis de uma passagem tranqüila para o socialismo, caso leve em conta o fato de que o Estado burguês organiza a dominação da classe capitalista e não pode ser mantido na transição. Além disso, considerar possível que o socialismo possa ser construído nos interstícios do capitalismo, levando em conta tão somente o estágio de desenvolvimento das forças produtivas - a revolução tecnológica com base na microeletrônica -, ou as experiências cooperativistas inseridas no mercado capitalista, é difundir a ilusão de que os problemas enfrentados pela classe operária no presente possam ser facilmente contornados.

Face aos limites impostos por uma comunicação, não pudemos abordar a questão da implicação recíproca das instâncias na reprodução do modo de produção, e, como decorrência, não foi possível analisar as relações entre o desenvolvimento das forças produtivas e desenvolvimento dos antagonismos de classe. Apenas deixaremos aqui registrado que o funcionamento das estruturas não é contraditório. Os efeitos deste funcionamento é que são contraditórios no longo prazo. Estas contradições levam ao

$-\cdots-\cdots$

11 Armando Boito Jr., “Os tipos de Estado e os problemas da análise poulantziana do Estado absolutista”. In: Crítica Marxista, n.7, São Paulo, Editora Xamã, 1998, p.87.

cadernos cemarx, $n^{0} 2-2005 \mid 99$ 
acirramento dos conflitos de classe, caracterizando a luta de classes no momento da transição de um modo de produção a outro. Assim, a instância econômica fornece a base material para a emergência dos conflitos de classe; e a luta de classes possibilita a transformação - por antecipação - da estrutura política, através da revolução - proletária, no caso da transição do modo de produção capitalista para o socialista, como indica Balibar no seu texto. Assim, reiteramos não ser possível a transformação da sociedade capitalista sem a tomada do poder político pela classe operária e a conseqüente destruição do Estado capitalista.

$1 \overline{00}$ O novo socialismo utópico e a importância da revolução política para o socialismo marxista 